Manoel Antônio dos Santos ${ }^{1}$

Marília Hormanez ${ }^{1}$

${ }^{1}$ Departamento de Psicologia, Faculdade de Filosofia Ciências e Letras de Ribeirão Preto,

Universidade de São Paulo. Av. Monte Alegre, 3900

14.040-901 Ribeirão Preto

SP. masantos@ffclrp.usp.br

\section{Atitude frente à morte em profissionais e estudantes de enfermagem: revisão da produção científica da última década}

\author{
The attitude among nursing professionals and students when facing \\ death: a review of the scientific literature of the last decade
}




\section{Introdução}

A morte não é somente um evento biológico natural e inevitável da vida humana, mas um processo construído socialmente ${ }^{1}$ e que, em decorrência disso, assumiu diversas representações coletivas nas sociedades ocidentais ao longo da história ${ }^{2}$. Até meados da Idade Média, a morte era vista como evento natural, cercado de rituais públicos; ao doente era permitido despedir-se da família e dos amigos, e determinar o que ainda era possível nesse processo ${ }^{3}$. O corpo morto, por sua vez, era visto como detentor de humanidade e personalidade ${ }^{2}$.

A partir do século XX, a morte começou a ser compreendida como um evento vergonhoso, que necessita ser escamoteado de todos a fim de garantir a impressão de que nada mudou. Nesse cenário em transformação, a morte, que não deveria ser percebida, deixou de ser um fenômeno natural, para ser vista como sinônimo de fracasso, impotência ou imperícia ${ }^{4}$. Com o advento do capitalismo, os valores humanos passaram a ser mensurados com base no lugar que cada pessoa ocupa no sistema produtivo; neste contexto, a morte ganha importância e dramaticidade, sustentadas pelas consequências econômicas que pode suscitar 5 .

Em decorrência dos avanços tecnológicos, a medicina também contribuiu para consolidar uma mudança decisiva na representação coletiva da morte. Os rituais fúnebres públicos não eram mais cabíveis, uma vez que não se morre mais em casa rodeado por familiares e amigos, e sim, às escondidas, junto à equipe de saúde, no silêncio asséptico dos hospitais. Ali, na maioria das vezes, o paciente se encontra passivo diante das decisões médicas, em plena ignorância e sem exercer qualquer controle sobre seu processo de morrer ${ }^{6}$. A presença da morte nesse ambiente é escamoteada e dissimulada pela equipe de saúde, que dificilmente admite a terminalidade do paciente e, quando o inevitável acontece, reage rapidamente para se desembaraçar do morto por meio de procedimentos burocráticos e técnicos. Essa urgência para descartar o corpo sem vida pode ser constatada nas expressões coloquiais utilizadas para designar o evento morte, como "o paciente foi a óbito" ${ }^{3}$ e para lidar com o morto como um "cadáver", às vezes designado como "pacote".

O imaginário coletivo construído em torno da morte a concebe como inimiga e indesejável, devendo ser evitada a qualquer custo. Em consequência do desenvolvimento científico e tecnoló- gico, os profissionais de saúde adquiriram poder para controlar, por meio da antecipação ou prolongamento, o momento da morte do paciente, o que reforça a crença de que se tornaram os donos da vida e da morte ${ }^{7}$. A partir do poder que têm em suas mãos, e influenciados por suas convicções profissionais, esses profissionais contribuem, muitas vezes, para a instauração de um processo de obstinação terapêutica. Nesse processo, o cuidado é direcionado para manter a vida a qualquer custo, sem se preocupar com sua qualidade, deixando de oferecer uma boa morte aos pacientes ${ }^{8}$.

Situada no ambiente hospitalar, a equipe de enfermagem mantém uma relação diferenciada com os pacientes que vivenciam a terminalidade e seus familiares. Enfermeiros são os profissionais de saúde que mais se mantêm em contato direto e prolongado com esses pacientes, sendo os primeiros que atendem suas necessidades ${ }^{4} \mathrm{e}$ que, consequentemente, estabelecem vínculos afetivos. Essa proximidade tanto pode ser benéfica para o cuidado, como pode torná-los vulneráveis ao estresse laboral. Por isso se torna relevante investigar os modos como significam a morte.

Ao permanecer próximo nos momentos difíceis, o profissional de enfermagem torna-se uma referência no cenário do cuidado; é a ele que o paciente e a família recorrem quando necessitam de esclarecimentos ou cuidados imediatos ${ }^{9}$. O enfermeiro torna-se, então, o primeiro profissional a lidar com o morrer e a morte ${ }^{1}$ e, consequentemente, o que está mais suscetível a níveis elevados de estresse.

Não obstante, durante a formação acadêmica do enfermeiro, o tema da morte e do morrer é pouco abordado. Persiste nos cursos de graduação dos profissionais de saúde uma ênfase excessiva na cura, que não raro passa a ser considerada como finalidade única do tratamento, associada à crença contemporânea na eficácia onipotente da tecnologia de última geração ${ }^{10}$. Assim, os profissionais vão se sentindo compromissados exclusivamente com a vida, e é para a preservação desta que se sentem capacitados ${ }^{1}$. Enfermeiros e médicos, já no primeiro ano do curso de graduação, durante as aulas de anatomia, são levados a lidar com a morte pela via da negação, por meio da despersonalização do paciente, que é significado como cadáver, órgãos e tecidos desvitalizados ${ }^{2}$. Esse prelúdio define os próximos movimentos, enquadrando a formação em saúde como um fazer tecnicista destituído de valores humanitários.

A deficiência na formação acadêmica perpassa o fazer do professor, fruto da mesma forma- 
ção desvirtuada. O docente, ao se sentir inseguro na abordagem do tema morte, tenta se proteger do contato com a dor e o sofrimento bloqueando sua sensibilidade, reprimindo as emoções suscitadas e desencorajando a reflexão sobre sua própria finitude. Por vezes, trata as situações de morte e morrer com impessoalidade, investindo mais na técnica dispensada e exigindo do aluno um comportamento voltado exclusivamente para o alívio do desconforto físico. Agindo assim, o docente acaba por não propiciar aos alunos espaço e oportunidade para refletirem sobre a morte ${ }^{11}$.

Nesse cenário, em uma perspectiva existencial, o profissional enfermeiro internaliza a crença de que seus sentimentos devem ser contidos perante o paciente ${ }^{12}$, em prol de uma postura firme e objetiva, que supostamente o imuniza contra o tão temido "erro" que paira como um eterno fantasma sobre o exercício profissional. Desse modo é construída a base valorativa da atitude frente à morte, que culminaria com ações de um profissional que tem a propensão de se mostrar "frio" ou indiferente na situação de terminalidade, uma vez que acredita que reconhecer o seu sofrimento significa mostrar-se vulnerável e ferir sua índole, colocando em risco a preservação do princípio da boa técnica.

O despreparo da equipe de saúde para lidar com situações de terminalidade tem como consequência, para os profissionais, a sensação de fracasso frente à missão de curar o doente ${ }^{3}$. De modo inexorável, a morte vem estabelecer os limites do saber e da ação do enfermeiro e do médico, desencadeando muitas vivências emocionais negativas associadas à frustração narcísica que ameaça a realização profissional. A finitude é apreendida não como uma parte do ciclo natural da vida, e sim como fracasso, derrota, vergonha, ruptura biográfica, entre outros significados negativos. Desse modo, o momento em que os profissionais se deparam com a iminência da cessação da vida é considerado terrível ${ }^{2}$. A dificuldade de manejar tal processo pode ocasionar, ainda, um distanciamento do paciente, como uma forma de defesa e proteção dos profissionais por não saberem enfrentar tal situação, por não conseguirem utilizar estratégias defensivas mais amadurecidas?.

A morte, além de suscitar profundo desapontamento nos profissionais no que diz respeito aos ideais de onipotência e eficiência inculcados desde a formação acadêmica, gera angústias existenciais advindas da projeção da fragilidade no outro e da identificação com o doente. Esse processo de identificação se torna mais acentuado quanto mais intensa é a projeção e deposição maciça da vulne- rabilidade no corpo doente. Falar da morte, abstrata ou específica, de alguém [...] é falar do que se está fazendo, do que não se fez, de planos, sonhos, perdas, do tempo que se foi, do que ainda resta; é disso que fugimos e tememos enfrentar. A morte do outro é uma lembrança da própria morte ${ }^{4}$.

A fim de proteger do contato com experiências dolorosas, a negação tem sido um dos mecanismos mais utilizados por estudantes e profissionais de enfermagem no enfrentamento de situações que envolvem a morte ${ }^{11}$. O sistema defensivo baseado na negação e repressão dos sentimentos e emoções alimenta o paradoxo de que, se por um lado os profissionais de saúde são os que mais intensamente lidam com o tema morte, por outro são também os que mais resistem em reconhecê-la como um fato inerente à existência humana ${ }^{13}$.

Ao lançar mão do mecanismo de negação da morte, além de não propiciar abertura ao paciente para falar e tomar conhecimento da questão o que, geralmente, é visto como pouco terapêutico, o profissional se torna vulnerável às graves consequências do luto mal elaborado, o que acentua sua vulnerabilidade ao entrar em contato com doenças e doentes ${ }^{1}$. Uma das decorrências possíveis dessa postura defensiva é a Síndrome de Burnout, que se refere ao desgaste e sofrimento do profissional suscitados pela exposição crônica aos estressores psicossociais presentes no desempenho das atividades laborais ${ }^{14}$. Os transtornos mentais também podem acometer o trabalhador de saúde, como a depressão que, atualmente, é o quadro psicopatológico que mais afeta os profissionais ${ }^{11}$. Estudo ${ }^{15}$ salienta ainda que o papel do enfermeiro, diferentemente do que se tem acreditado, não se esgota diante da morte, pois existe muito a ser feito pela família que necessita de cuidado e atenção para poder vivenciar esse momento de maneira mais equilibrada.

Ao considerar que a enfermagem é uma das profissões de saúde mais suscetíveis ao estresse laboral devido ao contato direto, intenso e prolongado com o paciente que vivencia a terminalidade $^{1,4}$, o presente estudo se propõe a compreender o repertório de atitudes dos profissionais e acadêmicos dessa área, entendendo por atitude a propensão à ação, ancorada em crenças e valores que configuram o marco da profissão na cultura brasileira.

Ainda que os resultados das pesquisas, tanto no cenário nacional como internacional, tendam a corroborar a vulnerabilidade mais acentuada dos enfermeiros face ao tema da morte, a literatura sistematizada ainda é escassa no que con- 
cerne ao conhecimento mais específico da atitude de profissionais e estudantes frente à finitude e suas implicações na prática profissional. Pautado nos aspectos apresentados, este estudo teve por objetivo investigar a atitude perante a morte entre profissionais e estudantes de enfermagem.

\section{Método}

Para alcançar o objetivo proposto, empreendeuse uma revisão integrativa da literatura científica nacional e internacional. A revisão integrativa foi eleita como método de pesquisa porque permite sumarizar estudos já finalizados acerca da temática abordada. Além disso, a revisão integrativa, quando elaborada de forma crítica, mantém os mesmos padrões de rigor, clareza e replicabilidade das pesquisas primárias que ela reúne e sistematiza $^{16}$, possibilitando, por sua vez, a construção de uma análise criteriosa da produção científica, contribuindo para ampliar discussões sobre métodos e resultados, assim como prover reflexões e apontamentos valiosos para a realização de outras ${ }^{17}$.

Dessa maneira, buscou-se evidenciar o número de publicações na área investigada e o perfil dos estudos, a fim de identificar as tendências apontadas por essas publicações, bem como as lacunas do conhecimento acumulado, de modo a possibilitar maior direcionamento das pesquisas sobre o tema.

\section{Procedimento}

Para a elaboração da revisão integrativa foram considerados os procedimentos preconizados por Ganong ${ }^{16}$, como o estabelecimento de critérios para inclusão e exclusão dos estudos publicados e análise crítica dos seus resultados, além de cumprir as etapas: seleção da questão temática, estabelecimento dos critérios para extração da amostra dos estudos, análise e interpretação dos resultados, e apresentação da revisão.

A pergunta que norteou a revisão da literatura foi: qual é a atitude de profissionais e estudantes de enfermagem frente à morte?

A coleta de dados foi realizada no período de janeiro a março de 2012. Para a busca dos artigos indexados foram utilizados os descritores Nurses e Attitude to death, de acordo com o DeCS - Descritores em Ciências da Saúde. Após o levantamento das publicações, os resumos foram lidos e analisados segundo os critérios de inclusão/exclusão preestabelecidos, que serão descri- tos na sequência. Em um segundo momento, os artigos foram recuperados na íntegra e examinados com o auxílio de um formulário elaborado para esse fim específico, constituindo o corpus de análise da revisão.

\section{Bases de dados consultadas}

Foram consultadas as seguintes bases indexadoras: MedLine, Lilacs, PsycINFO e CINAHL. Essas bases foram escolhidas a partir dos seguintes critérios: selecionou-se uma bibliográfica generalista, que inclui os resultados de pesquisa publicados na América Latina e do Caribe (Lilacs), duas internacionais que são consideradas referência na literatura em saúde (MedLine e CINAHL) e uma indexadora, também de âmbito internacional, que engloba publicações específicas da Psicologia e áreas afins (PsycINFO).

\section{Critérios de inclusão e exclusão das publicações}

Como critério de inclusão determinou-se: (1) artigos publicados no período de 2000 a 2011; (2) artigos redigidos em língua portuguesa, espanhola e inglesa; (3) que disponibilizavam o resumo na base de dados; (4) que relatavam a concepção subjetiva do enfermeiro ou do estudante de enfermagem frente à morte.

Foram excluídos os artigos que não atendiam às exigências anteriores; publicações que abordavam a postura técnica do profissional de enfermagem diante da morte, com caráter prescritivo e normativo, e trabalhos como teses, dissertações, livros, capítulos de livros, manuais, resenhas, críticas, comentários, editoriais, anais de eventos e relatórios científicos, a fim de realçar apenas os estudos submetidos a rigoroso processo de avaliação por pares (sistema de peer review). Foram selecionados, assim, exclusivamente artigos científicos publicados em periódicos indexados nas bases bibliográficas selecionadas.

\section{Resultados e Discussão}

A busca foi iniciada pelo Lilacs, base na qual foram encontrados 114 artigos, dos quais 46 foram selecionados pela pertinência aos critérios de inclusão e exclusão e 24 recuperados na íntegra. Em seguida procedeu-se a busca na base de dados MedLine, que gerou 1042 artigos, dentre os quais 177 foram selecionados e 15 recuperados, havendo exclusão de 13 artigos por repeti- 
ção com a outra base, restando apenas dois estudos. Na sequência foi consultada a base PsycINFO, na qual 57 artigos foram encontrados, 10 selecionados e cinco recuperados na íntegra. Para finalizar, realizou-se a busca pela base CINAHL, sendo encontrados 163 artigos, dos quais 29 foram selecionados e apenas quatro recuperados. Assim, dos 262 artigos preliminarmente selecionados, por meio da aplicação dos critérios de inclusão/exclusão, 35 foram coligidos, constituindo o corpus de análise que dá suporte à revisão. Esses dados podem ser melhor visualizados na Tabela 1.

Em relação às fontes de publicação, foi localizado um artigo em cada um dos seguintes periódicos: Ciencia y Enfermería, Revista Enfermagem UERJ, Arquivos de Ciências da Saúde, Scientia Medica, Oncology Nursing Forum, American Journal of Hospice \& Palliative Medicine, Patient Education and Counseling, Evaluation \& the Health Professions, Death Studies, International Journal of Older People Nursing, Journal of Hospice and Palliative Nursing, Nordic Journal of Nursing Research \& Clinical Studies, Australian Critical Care e International Journal of Qualitative Studies on Health and Well-being.

Foram encontrados dois artigos nos periódicos: Acta Paulista de Enfermagem, Revista Gaúcha de Enfermagem, Texto \& Contexto Enfermagem, Ciência, Cuidado e Saúde, Revista LatinoAmericana de Enfermagem e RENE: Revista da Rede de Enfermagem do Nordeste. Já na Revista Brasileira de Enfermagem foram encontrados quatro artigos e cinco na Revista da Escola de Enfermagem da USP. Observa-se, assim, que houve predomínio de períodos brasileiros, que correspondem a $47 \%$ das publicações encontradas.

Em relação ao país de origem do primeiro autor do estudo, o Brasil se encontra em primeiro lugar, com 24 autores, seguido dos Estados Unidos com três. Austrália, Chile, Holanda, In- glaterra, Japão, Singapura e Suécia aparecem com um autor.

No que diz respeito ao período de publicação (Figura 1), não foram encontrados artigos entre os anos de 2000 e 2004, o que sugere que o tema provavelmente ainda não despertava interesse na comunidade científica. Porém, esse quadro logo começaria a mudar: em 2005 foram encontrados três artigos, com aumento nos anos posteriores para sete artigos (2006, 2007, 2009 e 2010), ocorrendo uma redução somente no ano de 2008 (quatro artigos).

Os artigos foram classificados de acordo com os critérios estabelecidos por Polit et al. ${ }^{18}$. Todos os estudos analisados apresentam delineamento não experimental e transversal. A maioria (77\%) utiliza abordagem qualitativa, sendo que a mesma é predominante nos estudos brasileiros, correspondendo a $96 \%$ da produção encontrada. Em relação ao nível de evidência ${ }^{19}$, ou seja, a classificação da qualidade e força da evidência apresentada em uma escala de 1 a 6 , os estudos permaneceram no nível 4 (97\%). Essa categoria corresponde a estudos com desenho não experimental como pesquisa descritiva correlacional e qualitativa ou estudos de caso. No que diz respeito à população investigada, a maioria (71\%) se constitui de profissionais de enfermagem empregados em hospitais ou instituições de tratamento, sendo que apenas um artigo aborda o enfermeiro domiciliar e o da saúde da família; outros seis estudos abordam acadêmicos e dois investigam docentes de enfermagem.

Quanto aos objetivos, nota-se de modo geral que as publicações discorrem sobre: impressões, sentimentos e percepções dos profissionais de enfermagem e estudantes em relação à morte e ao morrer; condutas, atitudes e decisões em relação ao paciente que enfrenta o processo de morte e morrer; a preparação que os acadêmicos recebem para enfrentar a questão; as estratégias e

Tabela 1. Distribuição das referências encontradas nas bases de dados Lilacs, PsycINFO, MedLine e CINAHL no período de 2000 a 2011.

\begin{tabular}{cccccc}
\hline & & \multicolumn{4}{c}{ Artigos } \\
\cline { 3 - 6 } Base de dados & Descritores & Encontrados & Selecionados & Repetidos & Recuperados \\
\hline Lilacs & & 114 & 46 & - & 24 \\
MedLine & Nurses + & 1042 & 177 & 13 & 2 \\
PsycINFO & Atitude to death & 57 & 10 & - & 5 \\
CINAHL & & 163 & 29 & $-^{*}$ & 4 \\
\hline
\end{tabular}

"Na busca na base de dados CINAHL foi selecionada a opção "excluir artigos do MedLine”, o que tornou desnecessária a exclusão posterior dos artigos repetidos. 


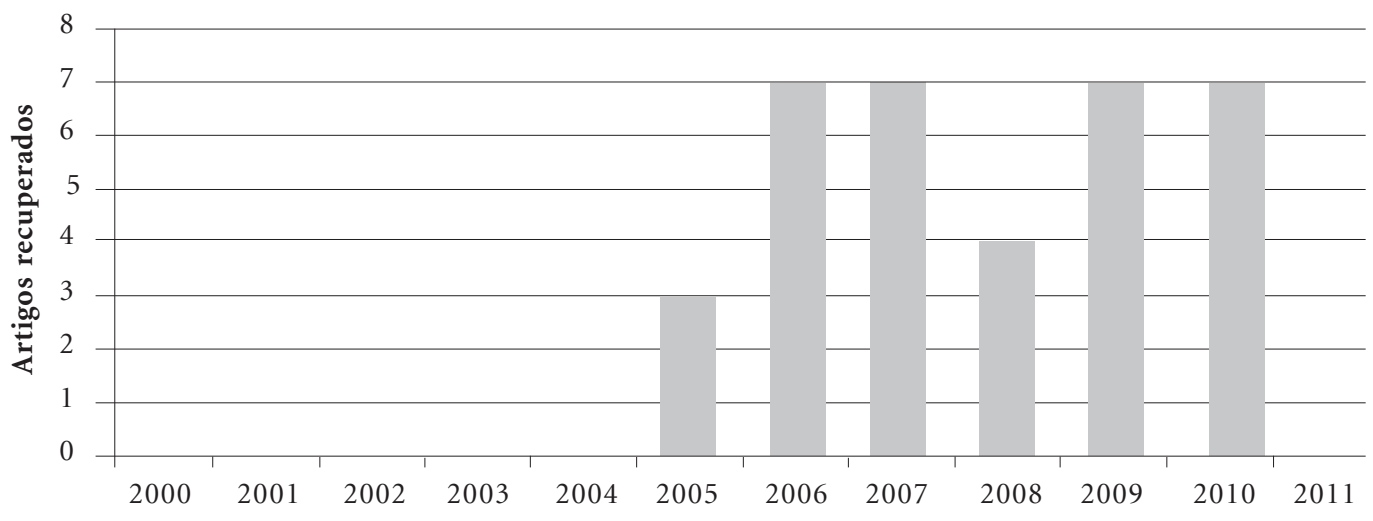

Ano de publicação

Figura 1. Distribuição dos artigos selecionados em relação ao ano de publicação.

os mecanismos de defesa utilizados quando vivenciam o processo de morte de um paciente; a relação entre docente e aluno que estão expostos à situação da morte e o modo como os profissionais vivenciam o luto pela morte dos pacientes.

Em relação aos instrumentos utilizados para a coleta de dados, a maior parte dos estudos fez uso de entrevistas (22), sendo que $31 \%$ utilizaram entrevista aberta e $28 \%$ roteiro semiestruturado. Seis estudos utilizaram questionários autoaplicáveis, dois com perguntas abertas e quatro com perguntas fechadas. Três aplicaram escalas de atitude, dois optaram pela dinâmica de grupo e apenas um utilizou o método etnográfico.

Os resultados dos estudos indicaram, de modo geral, que a morte é representada de variadas maneiras entre os estudantes ${ }^{1,3}$ e profissionais de enfermagem ${ }^{2,4,9,20-22}$. O final da vida é concebido como transição, passagem para a vida eterna, separação, perda, dor, incógnita, alívio, dever cumprido, como processo natural relacionado ao desenvolvimento do ser humano ou simplesmente como fim. Essas representações convergem para a maneira como cada indivíduo lida com a morte e o morrer ${ }^{1}$, ou seja, as formas adotadas para enfrentar essas situações. Estudo com profissionais de enfermagem da Suécia ${ }^{23}$ corrobora essa afirmação, uma vez que sustenta que os conhecimentos de vários aspectos emocionais dos profissionais constituem a base para a compreensão da prática dos cuidados em enfermagem.

Estudo com enfermeiros australianos ${ }^{24}$ mostra que os profissionais diferenciam a morte boa e a ruim, sendo que a boa morte ocorre quando existe a inclusão da família e do paciente nas decisões a serem tomadas, sua aceitação por todos os envolvidos e um ambiente apropriado de cuidados. A morte ruim é vista como aquela não esperada, na qual não se deu conhecimento ou reconhecimento de que a doença teve um avanço significativo; essa representação está muito ligada à negação, quando os profissionais não estão no controle do que está acontecendo, ignoram a realidade ou não se sentem capazes de conversar sobre os problemas, de maneira que acabam provendo uma visão amedrontadora da morte. A recusa de "deixar ir" não se aplica somente aos profissionais de saúde, mas também aos familiares e ao próprio paciente. Os enfermeiros sentem que, muito comumente, o paciente e a família negam-se a perceber o ocorrido e insistem na manutenção do tratamento, apresentando dificuldades em ouvir que a intervenção já é ineficaz, o que pode favorecer a adoção de medidas fúteis, abrindo caminho para a distanásia.

Em relação à atitude diante da morte e do morrer, grande parte das pesquisas apresenta a dificuldade encontrada pelos enfermeiros de se relacionarem com pacientes com prognóstico reservado e em fase terminal, uma vez que a proximidade da morte destes pode gerar sentimentos de impotência e culpa no profissional envolvido no cuidado ${ }^{25}$. A dificuldade não se restringe apenas ao manejo do paciente, mas também aparece no relacionamento com os familiares da pessoa que morreu ${ }^{1}$. 
Estudo brasileiro ${ }^{11}$ colocou o estudante de enfermagem diante de uma situação hipotética em que um paciente com morte iminente questiona o aluno a respeito de sua morte, foi encontrada forte tendência entre os acadêmicos de negar a morte, tentando afastar a ideia da mente do paciente e fazendo, por vezes, uso do senso comum em suas respostas ${ }^{11}$. Apenas uma pequena parcela de participantes relatou que enfrentaria a situação, conversando com o paciente sobre a questão, preocupando-se em ser acolhedora e proporcionar apoio emocional. Em estudo realizado com enfermeiras hospitalares ${ }^{8}$, relata que as profissionais reconhecem a necessidade de comunicar aos protagonistas do processo de morrer e morte sobre o diagnóstico e tratamento, mas essa temática aparece ainda bastante cristalizada entre elas como um tabu. As enfermeiras entendem como um ato de crueldade falar sobre a morte ou anunciar a morte futura para aqueles que ainda não estão preparados para aceitá-la e que se encontram na vigência de um processo de negação.

Em estudo realizado no Reino Unido ${ }^{26}$, abordando o convívio com pacientes idosos, os participantes reconheceram a importância da escuta e da conversa sobre a morte, mas não sabiam como poderiam colocar essa atitude em prática. Além disso, apontaram que a organização do ambiente de trabalho pode ser um empecilho, pois, muitas vezes, se encontram sem tempo para realizar essa aproximação com a delicadeza e disponibilidade que a situação exige.

Por outro lado, vários estudos mostram que os enfermeiros podem e devem se envolver afetivamente com o paciente em processo de morte e morrer $7,9,14,27,28$. Em alguns casos o envolvimento foi tão intenso que alguns profissionais acabaram associando os pacientes com membros da família ${ }^{4,10}$. O envolvimento aumenta ainda quando o paciente tem um tempo de permanência maior durante a internação, agravando, por sua vez, o sentimento de perda diante da morte. Outro fator que intensifica a dor pela morte de um paciente é quando se trata de uma criança,

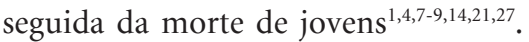

No que diz respeito à morte de crianças, estudo com profissionais de enfermagem de uma Unidade de Terapia Intensiva (UTI) neonatal mostrou que ela é encarada como uma inversão da ordem natural da vida, não sendo aceita, o que suscita sentimentos e emoções fortes, com os quais poucos sabem lidar, sendo a tristeza bastante enfatizada pelos participantes quando ocorre o desfecho fatal ${ }^{21}$. Além do envolvimento com os pacientes, os profissionais se vêem envolvidos com a família que enfrenta o processo de luto $^{27}$, sentem necessidade de oferecer apoio e de permanecerem próximos a fim de acolhê-la nesse momento doloroso ${ }^{4}$.

Em relação aos sentimentos despertados na ocorrência da morte de um paciente, estudo realizado junto a profissionais de enfermagem que atuam em UTI identificou que esses trabalhadores sofrem ao acompanhar o sofrimento dos pacientes diante do processo de morrer, sentimento que se agrava quando os perdem ${ }^{7}$. De acordo com o autor, estar diante da morte de um paciente é uma tarefa difícil para os enfermeiros, pois os expõem ao contato com a fantasia da própria morte, além de poderem reviver o término da vida de pessoas da família ou que lhes são próximas. Os participantes relataram também que não encontram espaço no âmbito familiar para a elaboração do sofrimento e da angústia produzidos no ambiente de trabalho. Tal consequência - a morte do paciente desencadear angústia frente à possibilidade da própria morte do cuidador formal, também aparece na visão de docentes de enfermagem ${ }^{29}$.

Diversos estudos evidenciam que os acadêmicos e profissionais de enfermagem, diante da ocorrência da morte de um paciente, sentem não ter cumprido seu objetivo de salvar vidas. A morte, desse modo, é significada como insucesso, gerando reações e sentimentos disfóricos como: tristeza, decepção, inconformismo, insatisfação, culpa, angústia, ansiedade, depressão, fragilidade, autorreprovação, baixa autoestima, dor, injustiça, desamparo, derrotismo, fracasso, impotência, choque, aversão, raiva, frustração, incerteza; tais sentimentos potencializam o medo humano da morte e a inquietação alimentada pelo desconhecimento sobre o que acontecerá após a morte $\mathrm{e}^{1,2,7,8,11,14,20,21,25,30}$.

Sentimentos similares são identificados também no paciente em fase terminal, que muitas vezes experimenta ansiedade, depressão, estresse, impotência, angústia, tristeza, dentre ou$\operatorname{tros}^{3,27}$. Tais emoções repercutem, por sua vez, na vida pessoal do profissional e do aluno, que procuram mobilizar suas defesas na tentativa de lidar com a situação sob o prisma racional ${ }^{31}$, levando-os a sentirem necessidade de contar com espaços no cotidiano profissional para reflexão e apoio emocional ${ }^{8}$.

Outra situação que desencadeia angústia e sofrimento é a necessidade de cuidar do paciente após a sua morte ${ }^{7}$. Esse procedimento é considerado de difícil habituação, pois é visto como inva- 
sivo, além de ser um momento crítico no que diz respeito à reflexão sobre a finitude de quem o realiza, incrementando estados de angústia. Os profissionais e os estudantes reconhecem, porém, que ao promoverem esse cuidado é primordial manter a seriedade, visto que entendem aquele corpo como um ser merecedor de respeito; assim, buscam realizar o cuidado da melhor maneira possível, com dignidade e consideração pelo sofrimento dos familiares e do próprio paciente ${ }^{4,20,27}$.

No que se refere à conduta em relação aos pacientes, estudo com estudantes de enfermagem relata que estes apresentam medo de expressar seus sentimentos diante dos pacientes, o que, para os autores, pode ser resultado do mito do enfermeiro capaz de se manter impassível diante da situação de morte 1 . Outro aspecto revelado por uma investigação ${ }^{13} \mathrm{com}$ profissionais de enfermagem empregados em UTI, é que estes percebem que o fato da equipe não aceitar a morte naturalmente faz com que se assuma uma postura de tentar salvar o paciente a qualquer custo, estabelecendo inúmeros procedimentos considerados medidas fúteis, que acabam resultando em prolongamento desnecessário do tempo para a morte e, consequentemente, induzem mais sofrimento tanto no paciente como na família e nos próprios profissionais ${ }^{8}$.

Estudo holandês, que investigou as decisões tomadas por profissionais de saúde em relação ao final da vida de pacientes com demência, constatou que as crenças religiosas influenciaram a tomada de decisão a respeito da manutenção da alimentação e hidratação artificial do doente, sendo que aqueles que declararam professar uma crença religiosa muitas vezes apresentaram uma atitude mais conservadora em relação a essas decisões ${ }^{32}$. Outros fatores que influenciaram as atitudes dos profissionais foram a diferença na perspectiva de vida do paciente, a diferença de responsabilidade entre os profissionais e o tempo de experiência dos mesmos. Estudo realizado com profissionais de enfermagem dos Estados Unidos $^{33}$ também mostrou que a concepção de morte influencia no estabelecimento de conversas com os pacientes sobre diretivas e providências antecipadas, sendo que os participantes que apresentaram uma ideia mais otimista em relação ao pós-morte iniciavam essas conversas com mais facilidade.

Ao abordarem a conduta de enfermeiros empregados em um centro de tratamento oncológico em relação aos pacientes em situação de terminalidade ${ }^{34}$, constatou-se que os participantes mais velhos (com 50 anos ou mais) apresentaram uma atitude mais positiva para cuidar desses pacientes do que os enfermeiros mais novos.

Corroborando esse achado, estudo com enfermeiros asiáticos concluiu que os profissionais seniores apresentavam atitudes mais positivas em situações de perda perinatal ${ }^{35}$. Outro fator, segundo a análise dos autores, que contribuiu para uma atitude positiva do profissional foi ter experiência prévia em lidar com pais em situação de luto.

Estudo realizado com enfermeiros empregados no Programa Saúde da Família ${ }^{28}$ revelou que, diante da peculiaridade do local em que o cuidado é realizado (na residência do paciente), ocorre maior proximidade física e emocional do enfermeiro com a família. Isso, por sua vez, influencia a conduta dos profissionais em relação ao cuidado prestado, que vai além do biológico, potencializando, assim, os recursos humanos que também são exigidos pela profissão.

Em estudo com enfermeiras que já estiveram, elas próprias, entre a vida e a morte ${ }^{36}$, foi constatado que essas profissionais, após vivenciarem a experiência de quase-morte, relataram mudanças em relação ao cuidado oferecido aos pacientes, passando a atendê-los com mais carinho e atenção, por compreenderem melhor suas emoções, sentimentos e receios. O fato de terem vivenciado a experiência de ser paciente em situação crítica propiciou aprofundamento do conhecimento dos sentimentos presentes nas pessoas hospitalizadas, tornando mais acessível a elaboração de um cuidado coerente com as reais necessidades dos pacientes, tanto fisiológicas quanto emocionais, espirituais e socioculturais. Uma das entrevistadas salientou que, a partir da experiência de ser paciente, conseguia reconhecer a importância, para os clientes, de terem a família por perto durante sua permanência na UTI.

Quanto aos familiares, estudo conduzido por Poles e Bousso ${ }^{15}$ com enfermeiros de UTI pediátrica mostrou que, para esses profissionais, quando o período de hospitalização é prolongado, há maior facilidade de conhecer os pais e desenvolver um relacionamento mais próximo com eles, o que traz confiança para abordá-los durante o processo de morte da criança, uma vez que já conhecem suas possíveis reações. Assim, a participação no processo de morte da criança junto à família pode ser meramente física e distante, quando a enfermeira tenta se preservar do medo da reação da família, ou pode ter real intimidade, quando o profissional se sente confortável para exprimir o desejo de querer ajudar, entender o sofrimento e ainda demonstrar seus próprios sentimentos aos familiares. 
Outros estudos relatam que os estudantes ${ }^{31} \mathrm{e}$ profissionais ${ }^{2}$ identificam-se com os familiares, percebem seu sofrimento e sua necessidade de atenção. Muitas vezes, os profissionais agem aproximando a família do paciente no momento da morte, promovendo a despedida. Buscam proporcionar uma experiência menos dolorosa para os familiares, tendo um cuidado especial na transmissão da notícia da morte, no preparo do ambiente e na garantia de privacidade, assim como no respeito ao tempo necessário para a despedi$\mathrm{da}^{8,15}$. A organização do trabalho, porém, é apontada como um empecilho quando os profissionais que desejam ter maior aproximação com os familiares, mas não encontram tempo devido à rotina sufocante de atividades laborais ${ }^{8}$.

No que diz respeito à preparação acadêmica, estudo realizado por Sadala e Silva ${ }^{31}$ com acadêmicos de enfermagem mostrou que estes se sentem despreparados para atender às exigências técnicas do cuidado com pacientes terminais, o que resulta em vivências de angústia e autoculpabilização. Os estudantes declararam que são raras as oportunidades oferecidas nos estágios para cuidarem de pacientes que se encontram no estágio final e que, quando o fazem, não se sentem orientados e apoiados. Os alunos mostraram preocupação em relação às deficiências em sua formação profissional e à falta de capacitação dos professores para abordar o tema.

Outra investigação com acadêmicos revelou que os estudantes têm expectativas quanto ao oferecimento, pelo curso de graduação, de subsídios para lidar com a morte. Porém, quando indagados a respeito das fontes de informações relacionadas ao tema, religião e filmes apareceram muito à frente do curso de graduação, o que indica, possivelmente, que não encontram em sua educação formal os subsídios necessários para suprirem suas necessidades de formação nessa área 3 .

Os resultados de pesquisas realizadas junto aos profissionais também são unânimes no que se refere às deficiências enfrentadas no decurso da formação acadêmica. Estudo aplicou um questionário de Atitude para a Morte ${ }^{37}$ e constatou que $81,53 \%$ dos enfermeiros apresentaram uma relação negativa diante da morte, associada a uma preparação avaliada entre pobre e regular no decorrer do curso de graduação para lidar profissionalmente com essa temática. Adicionalmente, 69,43\% reconhecem que, na instituição na qual trabalham, não existem sistemas de apoio aos profissionais que enfrentam a morte no dia a dia. Considerações produzidas em outra investigação ${ }^{4}$ complementam esses achados, afir- mando que, em decorrência da falta de reflexão e do total silêncio das universidades em relação à questão, muitos enfermeiros sentem-se despreparados para lidar com situações que implicam no enfrentamento da morte e do morrer. A maioria dos profissionais que participou do referido estudo informou que não teve embasamento teórico ou vivência prática sobre tanatologia durante a faculdade. Todos relataram a importância de aprofundar o tema morte na faculdade.

Esse quadro não se limita, porém, ao cenário latino-americano. Estudo realizado na Suécia ${ }^{38}$, com profissionais de enfermagem de uma unidade coronariana, apontou para o pouco preparo acadêmico recebido pelos mesmos, visto que apenas 26\% dos 63 entrevistados expressaram adequação educacional, isto é, afirmaram que receberam treinamento adequado para lidar com situações de morte.

Diversos estudos apontam que, em consequência dessa deficiência na formação, o profissional, ao se deparar com a morte, experimentará decepção e impotência ${ }^{20,27}$. Diante da concepção transmitida aos alunos de que o objetivo do cuidar é sempre salvar a vida, estes não conseguem visualizar e valorizar outras perspectivas para o atendimento oferecido, tais como saber ouvir o paciente, entender suas necessidades e oferecer-lhes os cuidados paliativos para ajudálo em sua trajetória final ${ }^{31}$. Em pesquisa com docentes de enfermagem ${ }^{29}$, os professores relataram que sentem necessidade de trabalhar a morte com os alunos, mas não sabem como fazêlo e, ao mesmo tempo, angustiam-se diante da temática, deixando transparecer, assim, ansiedade, solidão e ceticismo em relação à sua capacidade de ação nessa circunstância.

Outro estudo, realizado com docentes de enfermagem $^{6}$, corrobora esse achado. Os autores relatam que o docente, apesar de sua longa experiência, mostra-se desconfortável diante da morte e, ao lado do acadêmico, encontra ainda mais dificuldade por ter que ampará-lo e ensiná-lo sobre o processo da morte e do morrer, ao mesmo tempo em que sente necessidade de camuflar ou suportar de forma estoica sua própria angústia. Para driblar a inabilidade e a falta de preparo para ensinar sobre a morte e o morrer, o docente se vê aliviado ao poder enfatizar os aspectos técnicos, constituindo um fazer desconectado do sentir, o que torna o exercício da docência funcionalista e tecnicista.

Em relação aos mecanismos de defesa e às estratégias utilizadas no enfrentamento da morte, grande parte dos estudos revela que sua nega- 
ção é muito presente entre os profissionais de saúde e os acadêmicos, que não se encontram preparados emocionalmente para enfrentá-la e para lidarem com os próprios sentimentos ${ }^{6,9,21}$. No entanto, para outro estudo ${ }^{7}$, a negação dificulta tanto a aceitação quanto a elaboração da perda dos pacientes que morrem. Esses profissionais acabam supervalorizando as habilidades técnicas e os procedimentos burocráticos, buscando racionalizar a morte ${ }^{2,28,30} \mathrm{e}$, por vezes, demonstrando certa banalização, principalmente quando afirmam que vivenciar a morte cotidianamente passou a ser uma rotina ${ }^{27}$ ou quando preferem permanecer distantes do sofrimento dos pacientes, mantendo uma postura fria e indiferente diante dos sentimentos e da dor alheia ${ }^{8,27}$. No ambiente hospitalar existe uma certa regra de que o bom profissional não se envolve emocionalmente com o objeto de cuidado4. Desse modo, não há um espaço permissivo para que o profissional expresse seus sentimentos, o que pode desencadear defesas como distanciamento, frieza frente às situações ou, ainda, um equilíbrio apenas aparente, superficial, suficiente apenas para manter o status quo. A visão de que o profissional deve se manter "frio" ou indiferente nas situações de morte acarreta, muitas vezes, em luto mal resolvido ${ }^{14}$.

Outra estratégia de enfrentamento que aparece com frequência nos estudos é o apego à religião ou à fé $\mathrm{f}^{7,2,25,27,30,39,40}$. A espiritualidade, muitas vezes, auxilia o enfermeiro a assumir uma postura de aceitação diante da morte, uma vez que o óbito passa a ser entendido como uma transição espiritual ${ }^{2,21}$. Além disso, os profissionais podem se apegar a sua própria experiência profissional a fim de encarar a morte com mais naturalidade ${ }^{8} \mathrm{ou}$, ainda, podem acreditar que já cumpriram sua missão em relação ao paciente ${ }^{27}$. Em estudo realizado com enfermeiros de uma UTI pediátrica ${ }^{15}$, constatou-se que uma das estratégias utilizadas pelos profissionais diante do falecimento de uma criança era rever os próprios sentimentos e seu conceito de morte, além de se convencerem de que esta era inevitável, o que os afastava dos sentimentos de autoculpabilização e responsabilidade pessoal pelo desfecho. Um caminho de amadurecimento e mudança, apontado pelas autoras, surge quando esses profissionais percebem que seu trabalho vai além da morte da criança e que suas atividades podem ser mais abrangentes, contemplando também as necessidades da família enlutada.

Um achado interessante a respeito dos profissionais de enfermagem que trabalham em $\mathrm{UTI}^{13}$ é que eles acreditam que o relacionamento com a equipe multiprofissional interfere negativamente no processo de morte e morrer dos pacientes. Os enfermeiros relataram que a equipe médica pouco valoriza as diferenças disciplinares e que não os deixa a par das decisões e informações, de modo a não haver espaço para opinarem, o que gera sentimentos de frustração, insatisfação e desânimo. Os participantes declararam, ainda, que a equipe médica muitas vezes tem dificuldade de perceber que o ato de cuidar não consiste apenas em salvar vidas a qualquer preço, mas implica, antes de tudo, em preservá-la com a dignidade e respeito que merece.

Outro estudo realizado com enfermeiros lotados em UTI evidenciou o incômodo dos profissionais em relação ao poder exercido pelo médico no contexto hospitalar, especialmente no que se refere a condutas relacionadas à utilização ou não de técnicas de ressuscitação cardiopulmo$\operatorname{nar}^{27}$. Nesse sentido, estudo realizado junto a enfermeiros japoneses ${ }^{41}$ ajuda a problematizar essa questão, uma vez que os autores destacam como a maior descoberta de sua investigação o impacto da autonomia da enfermagem nas atitudes de enfermeiros em relação aos pacientes terminais. Assim, fortalecer essa autonomia seria importante para aprimorar os cuidados dispensados aos pacientes em situação terminal.

\section{Considerações finais}

Na revisão empreendida pôde-se constatar um incremento, nos últimos anos, no número de publicações em revistas indexadas nas bases de dados utilizadas. Esse dado pode denotar interesse crescente da comunidade científica em relação ao tema. Pôde-se verificar também o predomínio de publicações brasileiras, o que sugere que $\mathrm{o}$ assunto tem despertado a atenção dos pesquisadores no Brasil. Deve-se, contudo, considerar os limites da revisão efetuada, como o número limitado de bases de dados consultadas. Assim, o que se pode afirmar é que, considerando os limites das bases utilizadas, a maioria das referências é de autores brasileiros. Esse resultado indica que tem sido produzido um conhecimento favorecedor de maior percepção, por parte dos enfermeiros e docentes, de seu papel na promoção de condições apropriadas de trabalho e de formação e qualificação profissional.

A literatura científica analisada possibilitou evidenciar, de modo consistente, que o assunto morte e morrer vem sendo negligenciado nas instituições de formação, o que repercute em ten- 
sões que incidem na prática profissional. Como decorrência da falta de preparo, afloram dificuldades e sofrimentos vivenciados pelos profissionais e estudantes de enfermagem que, muitas vezes, acabam por recorrer a soluções solitárias no enfrentamento das questões mobilizadoras de inquietação. A pouca atenção conferida à temática repercute sobre a conduta adotada frente ao paciente que, por vezes, se torna fria, distante, impessoal e tecnicista. A exposição contínua e constante ao estresse gerado pelo contato cotidiano com a morte e o morrer dos pacientes, sem que haja dispositivos protetores institucionalizados para seu alívio e elaboração, pode afetar a saúde mental dos profissionais.

Frente aos resultados sistematizados, percebe-se a necessidade de futuras investigações acerca da temática, que sejam propositivas no sentido de testarem propostas e modelos de intervenção, tanto no plano da formação acadêmica como do treinamento continuado dos profissionais, visando, entre outros propósitos, a reestruturação dos currículos dos cursos de enfermagem e a capacitação dos docentes para abordar o assunto. É urgente que se recupere a questão da capacitação profissional, focada no desenvolvimento de habilidades e atitudes, inclusive para a tomada de decisão no fim da vida, além de programas de treinamento prévio ao início da prática profissional como parte da educação dos enfermeiros. A implantação de programas centrados na educação para a morte e de estratégias de resolução de problemas pode contribuir para a constituição de redes sociais e ampliar os espaços de discussão, nos quais os profissionais da área e os estudantes possam refletir sobre as questões ligadas à morte de forma saudável, vivencial, acolhedora e integrada.

\section{Colaboradores}

MA Santos foi responsável pela concepção do projeto, delineamento metodológico do estudo, análise e interpretação dos dados, elaboração da redação final do texto e aprovação da versão final do artigo. M Hormanez foi responsável pela pesquisa bibliográfica, análise e interpretação dos dados, e elaboração da versão preliminar do texto.

\section{Agradecimentos}

Ao financiamento do Conselho Nacional de Desenvolvimento Científico e Tecnológico (CNPq), Bolsa de Produtividade em Pesquisa.

\section{Referências}

1. Oliveira JR, Brêtas JRS, Yamaguti L. A morte e o morrer segundo representações de estudantes de enfermagem. Rev Esc Enferm USP 2007; 41(3):386-394.

2. Nascimento CAD, Silva AB, Silva MC, Pereira MHM. A significação do óbito hospitalar para enfermeiros e médicos. Rev RENE 2006; 7(1):52-60.

3. Takahashi CB, Contrin LM, Beccaria LM, Goudinho MV, Pereira RAM. Morte: percepção e sentimentos de acadêmicos de enfermagem. Arq Ciênc Saúde 2008; 15(3):132-138.

4. Aguiar IR, Veloso TMC, Pinheiro AKB, Ximenes LB. O envolvimento do enfermeiro no processo de morrer de bebês internados em Unidade Neonatal. Acta Paul Enferm 2006; 19(2):131-137.

5. Oliveira WIA, Amorim RC. A morte e o morrer no processo de formação do enfermeiro. Rev Enferm UERJ 2008; 16(2):243-248.

6. Pinho LMO, Barbosa MA. A relação docente-acadêmico no enfrentamento do morrer. Rev Esc Enferm USP 2010; 44(1):107-112.

7. Shimizu HE. Como os trabalhadores de enfermagem enfrentam o processo de morrer. Rev Bras Enferm 2007; 60(3):257-262.

8. Rosa AF, Lunardi VL, Barlem ED, Filho WDL. Percepções das enfermeiras frente aos sentimentos de quem vivencia o processo de morrer e morte. Ciênc Cuid Saúde 2006; 5(2):204-211.

9. Souza DM, Soares EO, Costa KMS, Pacífico ALC, Parente ACM. A vivência da enfermeira no processo de morte e morrer dos pacientes oncológicos. Texto Contexto Enferm 2009; 18(1):41-47. 
10. Rockembach JM, Casarin ST, Siqueira HCH. Morte pediátrica no cotidiano de trabalho do enfermeiro: sentimentos e estratégias de enfrentamento. Rev RENE 2010; 11(2):63-71.

11. Vargas D. Morte e morrer: sentimentos e condutas de estudantes de enfermagem. Acta Paul Enferm 2010; 23(3):404-410.

12. Silva KS, Ribeiro RG, Kruse MHL. Discursos de enfermeiras sobre morte e morrer: vontade ou verdade? Rev Bras Enferm 2009; 62(3):451-456.

13. Sanches PG, Carvalho MDB. Vivência dos enfermeiros de unidade de terapia intensiva frente à morte e o morrer. Rev Gaúcha Enferm 2009; 30(2):289-296.

14. Costa JC, Lima RAG. Luto da equipe: revelações dos profissionais de enfermagem sobre o cuidado à criança/adolescente no processo de morte e morrer. Rev Latino-Am Enferm 2005; 13(2):151-157.

15. Poles K, Bousso RS. Compartilhando o processo de morte com a família: a experiência da enfermeira na UTI pediátrica. Rev Latino-Am Enferm 2006; 14(2):207-213.

16. Ganong LH. Integrative reviews of nursing research. Res Nurs Health 1987; 10(1):1-11.

17. Fernandes LM. Úlcera de pressão em pacientes críticos hospitalizados: Uma revisão integrativa da literatura [dissertação]. Ribeirão Preto (SP): Universidade de São Paulo; 2000.

18. Polit DF, Beck CT, Hungler BP. Fundamentos de pesquisa em enfermagem: métodos, avaliação e utilização. Porto Alegre (RS): Artmed; 2004.

19. Galvão CM, Sawada NO, Mendes IAC. A busca das melhores evidências. Rev Esc Enferm USP 2003; 37(4):43-50.

20. Salomé GM, Cavali A, Espósito VHC. Sala de Emergência: o cotidiano das vivências com a morte e o morrer pelos profissionais de saúde. Rev Bras Enferm 2009; 62(5):681-686.

21. Silva LCSP, Valença CN, Germano RM. Estudo fenomenológico sobre a vivência da morte em uma unidade de terapia intensiva neonatal. Rev Bras Enferm 2010; 63(5):770-774.

22. Witternberg-Liles EM, Greene K, Sanchez-Reilly S. The palliative power of storytelling: using published narratives as a teaching tool in end-of-life care. $J$ Hospice Palliat Nurs 2007; 9(4):198-205.

23. James I, Andershed B, Gustavsson B, Ternestedt BM. Emotional knowing in nursing practice: in the encounter between life and death. Int J Qualitative Stud Health Well-being [Periódico na Internet]. 2010 [acessado 2013 abr 12]; 5:5367. Disponível em: http:/ /www.ijqhw.net/index.php/qhw/article/view/5367/ 5787

24. Borbasi S, Wotton K, Redden M, Chapman Y. Letting go: a qualitative study of acute care and community nurses' perceptions of a 'good' versus a 'bad' death. Aust Critic Care 2005; 18(3):104-113.

25. Brêtas JRS, Oliveira JR, Yamaguti L. Reflexões de estudantes de enfermagem sobre a morte e o morrer. Rev Esc Enferm USP 2006; 40(4):477-483.

26. Clark A, Ross H. Influences on nurses' comunications with older people at the end of life: perceptions and experiences of nurses working in palliative care and general medicine. Int J Older People Nurs 2005; 1(1):34-43.
27. Sulzbacher M, Reck AV, Stumm EMF, Hildebrandt LM. O enfermeiro em Unidade de Tratamento Intensivo vivenciando e enfrentando situações de morte e morrer. Sci Med 2009; 19(1):11-16.

28. Valente SH, Teixeira MB. Estudo fenomenológico sobre a visita domiciliária do enfermeiro à família no processo de terminalidade. Rev Esc Enferm USP 2009; 43(3):655-661.

29. Carvalho MDB, Valle ERN. Vivência da morte com o aluno na prática educativa. Ciênc Cuid Saúde 2006; 5(Supl.):26-32.

30. Gargiulo CA, Melo MCSC, Salimena AMO, Bara VMF, \& Souza IEO. Vivenciando o cotidiano do cuidado na percepção de enfermeiras oncológicas. Texto Contexto Enferm 2007; 16(4):696-702.

31. Sadala MLA, Silva FM. Cuidando de pacientes em fase terminal: a perspectiva de alunos de enfermagem. Rev Esc Enferm USP 2009; 43(2):287-294.

32. Rurup ML, Onwuteaka-Philipsen BD, Pasman HRW, Ribbe MW, van der Wal G. Attitudes of physicians, nurses and relatives towards end-of-life decisions concerning nursing home patients with dementia. Patient Educ Couns 2006; 61(3):372-380.

33. Black K. Health care professionals'death attitudes, experiences, and advance directive communication behavior. Death Stud 2007; 31(6):563-572.

34. Lange M, Thom B, Kline NE. Assessing nurses' attitudes toward death and caring for dying patients in a comprehensive cancer center. Oncol Nurs Forum 2008; 35(6):955-959.

35. Chan MF, Lou FI, Arthur DG. A survey comparing the attitudes toward perinatal bereavement care of nurses from three Asian cities. Eval Health Prof 2010; 33(4):514-533.

36. Pereira LA, Thofehrn MB, Amestoy SC. A vivência de enfermeiras na iminência da própria morte. Rev Gaúcha Enferm 2008; 29(4):536-542.

37. Cabrerra MM, Gutiérrez MZ, Escobar JMM. Actitud del professional de enfermeria ante la muerte de pacientes. Cienc Enferm 2009; 30(2):289-296.

38. Lundén K, Baigi IA, Hildingh C, Fridlund B. Coronary care unit nurses' outlook on death - their own thoughts as well as those of their patients: a pilot study. Nordic J Nurs Research Clin Stud 2007; 27(3):912.

39. Oliveira EA, Santos MA, Mastropietro AP. Apoio psicológico na terminalidade: ensinamentos para a vida. Psic em Est 2010; 15(2):235-244.

40. Santos MA. Perto da dor do outro, cortejando a própria insanidade: o profissional de saúde e a morte. Rev Spagesp 2003; 4(4):43-51.

41. Miyashita M, Nakai Y, Sasahara T, Koyama Y, Shimizu Y, Tsukamoto N, Kawa M. Nursing autonomy plays an important role in nurses' attitudes toward caring for dying patients. Amer J Hospice Palliat Med 2007; 24(3):202-210.

Artigo apresentado em 30/04/2013

Aprovado em 22/05/2013

Versão final apresentada em 27/05/2013 